\title{
Effect of high intensity interval training on diabetic obese women with polyneuropathy: a randomized controlled clinical trial
}

\author{
Nashwa Sayed Hamed ${ }^{1,2^{*}}$ and Neveen Abdel Latif Abdel Raoof ${ }^{3}$ \\ *Correspondence: nashwahamed@gmail.com

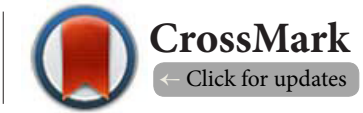 \\ 'Department of Neuromuscular Disorders and its Surgery, Faculty of Physical Therapy, Cairo University, ARE. \\ ${ }^{2}$ Physical Therapy Department, Faculty of Applied Medical Sciences, Taif University, KSA. \\ ${ }^{3}$ Department of Basic Sciences, Faculty of Physical Therapy, Cairo University, ARE.
}

\begin{abstract}
Purpose: To investigate the effect of high intensity interval training on diabetic obese women with polyneuropathy.

Methods: In rehabilitation clinics. A double blinded controlled randomized study including 40 type II diabetic women with polyneuropathy having class II central obesity, mean age $48.23 \pm 2.4$ years. Patients were randomized equally into Group (A); (study), received high intensity interval training on cycle ergometer and group (B); (control) received moderate intensity aerobic training for (3 times/week) for 15 weeks. Assessment performed before and after treatment using Leeds Assessment of Neuropathic symptoms and signs Scale for pain assessment. Other measures, lower extremity functional scale, body weight, body mass index, waist circumference, and oral glucose tolerance test.

Results: There were statistically significant improvement in favor of Group (A) compared to Group (B) in Leeds Assessment of Neuropathic symptoms and signs Scale results with a mean difference $(-3.6 \pm 0.7$ points), $(\mathrm{P} \leq 0.0001)$; waist circumference mean difference $(-1.13 \mathrm{~cm}),(\mathrm{P} \leq 0.017)$. Oral glucose tolerance test had $(\mathrm{P} \leq 0.0001)$ : FBG $(-6.5 \pm 2.9)(\mathrm{P} \leq 0.03), 60 \mathrm{~min}, 90 \mathrm{~min}$ and 120 min mean difference was $(-42.75 \pm 6.2 \mathrm{mg} / \mathrm{dl}),(-32.5 \pm 4.5 \mathrm{mg} / \mathrm{dl})$ and $(-20.15 \pm 2.2 \mathrm{mg} / \mathrm{dl})$ respectively. However, lower extremity functional scale, body weight and body mass index did not show a significant difference between both groups.

Conclusion: high intensity interval training was effective in reducing pain outcome and glucose tolerance in diabetic obese women with polyneuropathy compared to moderate aerobic intensity training.
\end{abstract}

Keywords: Polyneuropathy, neuropathic pain, high intensity interval traininfg, diabetes, women

\section{Introduction}

Diabetes is one of the leading causes of peripheral neuropathy which is a heterogeneous group of disorders that can affect neuronal function throughout the body. In the literature, the prevalence of diabetic neuropathy ranges from $10 \%$ to $20 \%$ of patients with diabetes. An estimated 50 percent of people with diabetes who have had the disease for at least 25 years have some form of peripheral diabetic neuropathy. The most important etiological factors with associated with poor glycemic control are diabetes duration, increased body mass index, visceral obesity, physical inactivity and poor nutrition. Other possible factors are hypertension, age, smoking, hypoinsulinemia, and dyslipidemia [1]. Females are more prone to diabetes due to increased prevalence of obesity and increased body mass index [2].

Peripheral diabetic neuropathy may be characterized by perceived numbness and diminished sensation with subsequent diabetic ulcers and non-traumatic amputations [3]. Moreover, falls among the elderly [4] and pain with or without motor weakness of extremities particularly legs and feet are common [5].
Long-standing peripheral neuropathic pain associated with peripheral neuropathy occurs in one of six diabetic subjects. Chronic painful diabetic peripheral neuropathy can cause symptoms that last for years and severely impair functional activities, and consequently the quality of life [6].

Many studies suggests exercises as a method of reducing neuropathic pain [7] and whole body fat mass in diabetic obese patients [8]. Exercises also have a positive effect on improving blood lipid profiles, blood pressure, resting heart rates, body composition as well as glycemic control [10]. Furthermore, glycemic control helps to improve signs and symptoms of peripheral neuropathy [11]. Contrary to regular moderate intensity aerobic exercises, high-intensity interval training or sprint interval training is a strategy of time-efficient, low volume and high intensity interval exercise sufficient to achieve significant improvements in glycemic control and whole body insulin sensitivity in sedentary obese adults $[12,13]$. Currently, due to hectic and busy life style, most individuals prefer time efficient exercise program that is significant in producing maximum results with economy in time and cost. 
Hamed et al. Physical Therapy and Rehabilitation 2014,

Thus, the aim of this study is to investigate the effect of high intensity interval training on diabetic obese women with peripheral neuropathy.

\section{Subjects and methods \\ Subjects}

Fifty eight female patients were assessed for eligibility in this study. Forty type Il diabetic women suffering from polyneuropathy were selected for this study from consequently admitted patients to the outpatient's clinics. Inclusion criteria were: class II central obesity, body mass index ranging from 35 to $39.9 \mathrm{Kg} / \mathrm{m}^{2}$ and waist circumference $>35$ inches $(88 \mathrm{~cm})$. Patient's ages ranged from 45-55 years. They had type II diabetes according to Oral Glucose Tolerance Test (i.e., impaired fasting glucose: $>100-125 \mathrm{mg} / \mathrm{dl}-2$ hour postprandial: 140-199 $\mathrm{mg} / \mathrm{dl}$ ). All patients were taking oral hypoglycemic medications only. Patients were suffering from neuropathic pain in their feet and hands in the form of glove and stockings. The diagnosis of painful diabetic neuropathy was proved with nerve conduction studies provided by a specialized neurologist. Severe diabetic polyneuropathic complications were excluded i.e., complete loss of sensory and motor function, (Figure 1).

Clinical diagnosis of painful diabetic polyneuropathy was proved if the pain was bilateral, in peripheral limbs (hands and feet), often worse at night, neither related to exertion nor caused by other conditions known to be present, such as arthritis, spondylosis, and peripheral vascular disease. Patients with peripheral diabetic polyneuropathy completed the Leeds Assessment of Neuropathic symptoms and signs Scale (LANSS pain scale) [13]. Twelve or more points were in the inclusion criteria of the patients which means that pain is due to a neuropathic origin. All patients were informed to

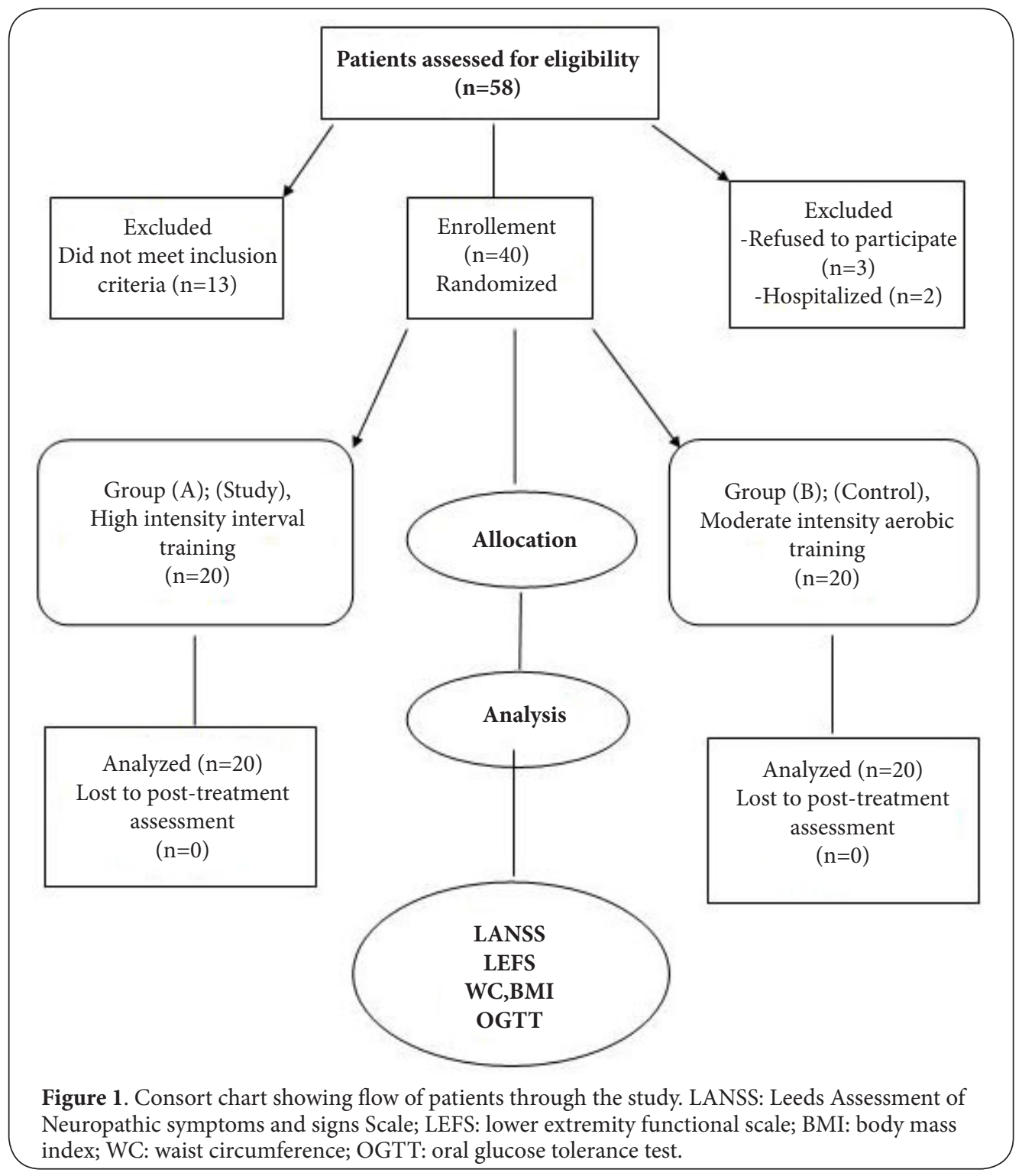


stop taking any pain medications one week before joining the training program. All patients had the ability to stand and walk.

Patients were classified to have moderate to minimal disability (60\%-80\% of disability score) according to lower extremity functional disability scale [14]. Exclusion were applied to smokers, suffering from any uncontrolled conditions (sever hypertension, renal failure, unstable angina, myocardial infarction, cardiovascular instability, autonomic neuropathy and musculoskeletal disorder). Patients were selected from endocrinology and/or neurology outpatient clinic of Kasr ELAini, Cairo University Hospitals and from Faculty of Physical Therapy Outpatient Clinic. Patients were assigned randomly into two equal groups. Group (B); (control), performed moderate intensity aerobic exercise on cycle ergometer and group (A); (study) performed high intensity interval training.

\section{Study design}

This was a double blinded controlled randomized study. The study sample was enrolled from consequently admitted patients numbered consequently on a prefilled envelops starting from one to 40 (total number of patients). Random number generator, using a special computer soft ware, was used to generate random numbers from the 40 patients sample. In a table, randomized numbers were stratified into two columns representing the two groups (high intensity interval training and moderate intensity aerobic training) with 20 rows representing the number of patients in each group. The procedures were carried out by the front admission office employees of the outpatient clinic of the faculty of physical therapy.

The Faculty of Physical Therapy Human Research Ethics Committee approved this project, and written informed consent was gained from all participants prior to their involvement in the study.

\section{Intervention}

Two well experienced physical therapists, of more than 20 years of experience, conducted the intervention protocol of this study. An initial meeting with the patients of each group and the therapists was conducted to explain the protocol of the exercises program they were involved in. The participants did not know whether they are in the study or the control groups. All participants received training for 3 non-consecutive days per week for 15 weeks. The instruments used for both groups were stationary bicycle ergometer (Spirit XBR95 Recumbent Bike; Italy) and Telemetry (Hewlett Packard (HP) M2604A made in U.S.A) a wireless device used to monitor heart rate and rhythm for four patients at the same time during activity.

Group (B): Moderate intensity aerobic training "MIAT"; Women enrolled in this group submitted a supervised moderate intensity aerobic exercise program. Each session lasted for 50 minutes, included 10 minutes pedaling on the cycle ergometer at low speed (30-40\% of maximum heart rate) as warming up followed by 30 minutes pedaling on the cycle ergometer with moderate intensity (50-60\% of maximum heart rate) as active training phase and finally 10 minutes pedaling at low speed (30-40\% of maximum heart rate) as cooling down [15].

Group (A): High intensity interval training "HIIT"; Women enrolled in this group submitted a 20 minutes session of high intensity interval training on stationary bicycle ergometer. Each session started with 5 min warming up pedaling at free speed. At the end of warming up, subjects followed a prerecorded tape, which included prompts to start and stop cycling with $8 \mathrm{~s}$ of sprinting and $12 \mathrm{~s}$ of low intensity cycling (turning the pedals over slowly, between 20 and 30 revolution per minute) for a maximum of 30 repeats a session with (85$95 \%)$ of maximum heart rate (MHR) and recovery (cooling down) for $5 \mathrm{~min}$ at (60-70\% MHR). At the end of the cooling down phase, subjects performed standard stretches for the quadriceps, hamstrings and posterior calf muscles [16]. Heart rate was recorded during warming up, the exercise phase and cooling down. During exercise, intensity was controlled by establishing target heart rate at the equivalent percentages of heart rate reserve, based on the resting and the maximum heart values measured during testing [17]. The heart rate monitor provides an audible feedback on reaching the target heart rate. The women reported reduction in pain intensity and adapted to the training rapidly. Therefore, by the end of 2 weeks (six exercise sessions); all women were able to complete the full $20 \mathrm{~min}$ of exercise.

For both groups of patients, after starting the exercise program with the desired workload (each patient chose her preferred work load), progressive increases in the exercise intensity were made at intervals throughout the training by adjusting the exercise workload to maintain heart rates within the initially prescribed ranges with $0.5 \mathrm{~kg}$ increments added to preserve the prescribed exercise intensity. If an individual missed a session, she would make it up later, so that 45 exercise sessions were completed within the 15-week period.

\section{Outcome measures}

Assessment was performed by two independent blind physical therapists on baseline and post-treatment intervention. Assessment procedures were performed for baseline measurements one day before the training program and for post treatment assessment one day after the intervention. The allocated patients were instructed to stop taking any pain medications for one week before the assessment protocol. The Leeds Assessment of Neuropathic symptoms and signs Scale (primary outcome measure) was used for pain assessment. This measure is a questionnaire composed of 7-item pain scale that contains grouped sensory description and sensory examination with a simple scoring system [18]. Patients were requested to rate their pain as No (0 points) or Yes with different rating scores $(1,2,3$ or 5 points) with maximum of 24 points. The first 5 questions ask for the presence of unpleasant skin sensations (pricking, tingling, pins and needles), appearance of the skin 
Hamed et al. Physical Therapy and Rehabilitation 2014,

http://www.hoajonline.com/journals/pdf/2055-2386-1-4.pdf

doi: $10.7243 / 2055-2386-1-4$

(mottled, red, or pink), increased sensitivity of the skin to touch, sudden bursts of electric shock sensations, and hot or burning skin sensations. The last 2 questions involve sensory testing for the presence of allodynia and altered pinprick threshold Different number of points, relative to their significance to neuropathic pain, are given to positive answers. A score of $<12$ points makes it unlikely that the patient's symptoms are neuropathic in nature. Whereas a score $>12$ points make neuropathic cause likely to be contributing to the patient's pain. The patients with neuropathic pain were noted to have more allodynia, hyperalgesia, or a raised pinprick threshold. The LANSS scale was noted to have $85 \%$ sensitivity, $80 \%$ specificity, and a predictive value of $82 \%[13,18]$.

\section{Secondary outcome measures}

Lower extremity functional scale: The measure is comprised of 20 items enquiring about difficulty performing a variety of everyday activities concerning the lower extremity [14]. Patients were asked to rate their lower extremity functional status starting from 0 (Extreme Difficulty or Unable to Perform Activity), 1 (quite a bit difficulty), 2 (moderate difficulty), 3 (a little bit difficulty) to 4 (no difficulty). Adding all the scores provided by the patients is the total lower extremity functional score which may vary from 0 (low) to 80 (normal function). The scale has high level of validity and reliability to all levels of function [19].

Anthropometric parameters: waist circumference was assessed by using tape measurement with a non-elastic material at the midpoint between the lower border of the ribcage and the iliac crest, and body mass index (BMI) was assessed by Standard Weight and height scale (Floor type Model ZT-120), consequently calculating the body mass index

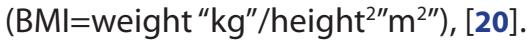

Oral glucose tolerance test: Patients were refrained from performing any strenuous physical activity for 2 days prior to the test, and attended the lab after overnight fasting (8-14h). Venous blood samples were collected by venipuncture. Three milliliters blood sample was drained under aseptic condition from each participant to perform the test. Repetition of the previous steps after $60 \mathrm{~min}, 90 \mathrm{~min}$ and $120 \mathrm{~min}$ post prandial to all participants [21], (Figure 1).

\section{Statistical analysis}

The characteristics of the studied group were summarized using descriptive statistics. Quantitative data are reported as means and standard deviations. The mean values of the Leeds Assessment of Neuropathic symptoms and signs Scale, lower extremity functional scale, body mass index, waist circumference, and oral glucose tolerance test obtained before and after 15 weeks in each group were compared using the paired " $\mathrm{t}$ " test. Unpaired " $\mathrm{t}$ " test was used for the comparison between the two groups (95\%) confidence interval. Only descriptive analysis was obtained for body weight measurements. Analysis was performed using graph pad prism version 5.0. (Graph Pad Software Inc 1998, San Diego, (A, USA).

\section{Results}

Baseline characteristics were compared in both groups with no statistical significant difference suggesting homogeneity between both groups. (Table 1) shows baseline and demographic data of all subjects $(P>0.05)$.

Table 1. Demographic and base line characteristics of the study participants.

\begin{tabular}{|c|c|c|c|}
\hline \multirow[t]{2}{*}{ Variable } & Group (A) $(n=20)$ & Group (B) $(n=20)$ & \multirow[t]{2}{*}{ p-value } \\
\hline & $\mathrm{X} \pm \mathrm{SD}$ & $\mathrm{X} \pm \mathrm{SD}$ & \\
\hline Age(year) & $48.25 \pm 0.63$ & $47.95 \pm 0.95$ & 0.48 \\
\hline Height $(\mathrm{cm})$ & $160 \pm 1.6$ & $164 \pm 1.2$ & 0.08 \\
\hline Body weight $(\mathrm{Kg})$ & $105 \pm 2.15$ & $100 \pm 2.9$ & 0.25 \\
\hline $\operatorname{BMI}\left(\mathrm{Kg} / \mathrm{m}^{2}\right)$ & $39.01 \pm 0.67$ & $39.14 \pm 0.87$ & 0.94 \\
\hline $\mathrm{WC}(\mathrm{cm})$ & $114.3 \pm 1.68$ & $116.4 \pm 1.85$ & 0.41 \\
\hline LANSS & $21.75 \pm 0.45$ & $21.80 \pm 0.42$ & 0.93 \\
\hline LEFS & $55.30 \pm 1.18$ & $56.35 \pm 1.24$ & 0.54 \\
\hline \multicolumn{4}{|l|}{ OGTT: } \\
\hline$-\mathrm{FBG}(\mathrm{mg} / \mathrm{dl})$ & $118.1 \pm 1.11$ & $116.8 \pm 1.37$ & 0.31 \\
\hline-60 -minute $\mathrm{PP}(\mathrm{mg} / \mathrm{dl})$ & $182.2 \pm 8.40$ & $206.2 \pm 5.55$ & 0.06 \\
\hline-90 -minute $\mathrm{PP}(\mathrm{mg} / \mathrm{dl})$ & $175.4 \pm 8.2$ & $188 \pm 3.75$ & 0.17 \\
\hline-120 -minute $\mathrm{PP}(\mathrm{mg} / \mathrm{dl})$ & $156.6 \pm 5.47$ & $166.45 \pm 2.2$ & 0.1 \\
\hline
\end{tabular}

$\mathrm{X}$ : mean; SD: standard deviation; BMI: body mass index; WC: waist circumference; LANSS: Leeds Assessment of Neuropathic symptoms and signs Scale; LEFS: lower extremity functional scale; OGTT: oral glucose tolerance test; FBG: fasting blood glucose; PP: post prandial

Out of 58 patients assessed for eligibility, forty (68\%) type II diabetic neuropathic women were included in this study; 13 patients (22\%) were excluded as they didn't meet the inclusion criteria. Three patients refuse to join the study (5\%) while 2 patients (3\%) joined the study but they did not complete because they were hospitalized. (Figure 1) shows the flow of patients through the study. Their ages ranged from 45-55 years with a mean age $48.23 \pm 2.4$. Patients were randomized into two groups: group (A) (GA) study group $(n=20)$ and group (B) (GB) control group $(n=20)$.

Primary outcome measure results, Leeds Assessment of Neuropathic symptoms and signs Scale (LANSS): most of patients reported reduction of pain almost after two weeks of treatment intervention. LANSS post-treatment results showed a significant difference between groups in favor of GA (study group) $(P \leq 0.0001)$, (Table 2 ).

\section{Secondary outcome measures}

Lower extremity functional scale (LEFS) did not show a significant difference between both groups in post treatment results $(P \leq 0.55)$. However, the change score were higher in group A (study group) 11.2 points compared to group B (control 
Hamed et al. Physical Therapy and Rehabilitation 2014,

http://www.hoajonline.com/journals/pdf/2055-2386-1-4.pdf

Table 2. Outcome measures after 15 weeks of intervention.

\begin{tabular}{|c|c|c|c|c|c|c|}
\hline \multirow{2}{*}{ Measure } & \multicolumn{2}{|c|}{$\begin{array}{c}\text { Group (A) }(\mathbf{n}=20) \\
X \pm S D\end{array}$} & \multicolumn{2}{|c|}{$\begin{array}{c}\text { Group (B) }(\mathbf{n}=20) \\
X \pm S D\end{array}$} & \multirow[t]{2}{*}{ Mean difference } & \multirow[t]{2}{*}{ p-value } \\
\hline & pre & post & pre & post & & \\
\hline Body weight(Kg) & $105 \pm 2.15$ & $94.75 \pm 1.9$ & $100 \pm 2.9$ & $94.15 \pm 3.1$ & $-0.6 \pm 3.7$ & 0.8 \\
\hline $\operatorname{BMI}\left(\mathrm{Kg} / \mathrm{m}^{2}\right)$ & $39.01 \pm 0.67$ & $35.45 \pm 0.59$ & $39.14 \pm 0.87$ & $36.59 \pm 0.98$ & $-1.13 \pm 1.1$ & 0.33 \\
\hline $\mathrm{WC}(\mathrm{cm})$ & $114.3 \pm 1.68$ & $102.8 \pm 1.5$ & $116.4 \pm 1.85$ & $109.4 \pm 2.15$ & $-6.5 \pm 2.6$ & 0.017 \\
\hline LANSS & $21.75 \pm 0.45$ & $16.85 \pm 0.69$ & $21.80 \pm 0.42$ & $20.45 \pm 0.37$ & $-3.6 \pm 0.7$ & 0.0001 \\
\hline LEFS & $55.30 \pm 1.18$ & $66.50 \pm 1.12$ & $56.35 \pm 1.24$ & $65.30 \pm 1.70$ & $1.2 \pm 2.03$ & 0.55 \\
\hline \multicolumn{7}{|l|}{ OGTT: } \\
\hline $\mathrm{FBG}(\mathrm{mg} / \mathrm{dl})$ & $118.1 \pm 1.11$ & $89.65 \pm 2.14$ & $116.8 \pm 1.37$ & $96.2 \pm 2.01$ & $-6.5 \pm 2.9$ & 0.03 \\
\hline 60-minute $\mathrm{PP}(\mathrm{mg} / \mathrm{dl})$ & $182.2 \pm 8.40$ & $120.5 \pm 4.6$ & $206.2 \pm 5.55$ & $163.3 \pm 4.17$ & $-42.75 \pm 6.2$ & 0.0001 \\
\hline 90-minute $\mathrm{PP}(\mathrm{mg} / \mathrm{dl})$ & $175.4 \pm 8.2$ & $115.6 \pm 3.6$ & $188 \pm 3.75$ & $148.5 \pm 2.5$ & $-32.85 \pm 4.5$ & 0.0001 \\
\hline 120 -minute $\mathrm{PP}(\mathrm{mg} / \mathrm{dl})$ & $156.6 \pm 5.47$ & $100 \pm 1.5$ & $166.45 \pm 2.2$ & $120.2 \pm 1.5$ & $-20.15 \pm 2.2$ & 0.0001 \\
\hline
\end{tabular}

$\mathrm{X}$ : mean; SD: standard deviation; MD: mean difference; BMI: body mass index;

WC: waist circumference; LANSS: Leeds Assessment of Neuropathic symptoms and signs Scale; LEFS: lower extremity functional scale; OGTT: oral glucose tolerance test;

FBG: fasting blood glucose; PP: post prandial

group) 8.95 points, (Table 2 ).

Concerning body weight and body mass index, there was no significant difference between both groups, $(P \leq 0.8)$ for body weight and $(P \leq 0.55)$ for $B M I$, with higher change score in favor of the group $A$ (study group) $-10.3 \mathrm{Kg}$ for body weight and $-3.6 \mathrm{~kg} / \mathrm{m}^{2}$ for body mass index. While group B (control group) change scores were $-6.6 \mathrm{~kg}$ for body weight and -2.5 $\mathrm{kg} / \mathrm{m}^{2}$ for body mass index, (Table 2 ).

Waist circumference comparison between both groups after treatment also showed a significant difference in favor of group $A$ (study group), with $-11.5 \mathrm{~cm}$ change score, while group $B$ (control group) change score was $-7 \mathrm{~cm},(P \leq 0.017)$, (Table 2).

There was a high statistical significant difference between groups as regards Oral glucose tolerance test after treatment compared to before treatment in favor of group A (study group), $(P \leq 0.03)$ for fasting blood sugar and $(P \leq 0.0001)$ for 60,90 and 120 post prandial, (Table 2 ).

\section{Discussion}

The current study employed a novel use of high intensity interval training in diabetic obese women with polyneuropathy compared with moderate intensity aerobic training after 15 weeks of intervention.

Consistent with the study hypothesis, high intensity interval training was found to be more efficient and had a significant difference in reducing the Leeds Assessment of Neuropathic symptoms and signs Scale scores, waist circumference, and oral glucose tolerance test (fasting, $60 \mathrm{~min}, 90 \mathrm{~min}$ and $120 \mathrm{~min}$ post prandial) relative to moderate intensity aerobic training. However, lower extremity functional scale, body weight and body mass index did not show a significant difference between both groups. However, the change scores were higher in favor of group A (study group).
The significant Reduction of pain (primary outcome measure) in both groups could be postulated to the effect of exercises on glycemic control, and consequently on the reduction of neuropathic pain. However, high intensity interval training group showed more significant reduction of pain compared to moderate intensity aerobic training.

Yet, there is strong evidence that good glycemic control can prevent the appearance and worsening of polyneuropathy in patients with insulin-dependent diabetes mellitus [22]. Shankarappa and et al., [23] were the first to demonstrate that forced-exercise markedly delays the onset of tactile hypersensitivity, a semi-quantitative behavioral measure of painful neuropathy, in experimentally-induced diabetic rats. The author proposed that forced-exercise delays the onset of diabetes-associated neuropathic pain, in part, by attenuating associated changes in high voltage activated and low voltage activated $\mathrm{Ca}^{2+}$ channel function within small-diameter dorsal root ganglion neurons possibly by altering opioidergic tone.

It is well established that moderate to high intensity exercise provokes measurable increases in circulating glucocorticoids in rodents and in humans which facilitate analgesia. Recent preliminary studies, with small cohorts of neuropathic diabetic patients, support a beneficial effect of exercise on some measures of peripheral nerve function and may even delay or protect against the development of diabetic peripheral nerve complications [24].

The mechanism by which painful peripheral neuropathy occurs in people with diabetes is not well-understood. However, abnormal activation of damaged or regenerating peripheral nerves may be involved. These nerves become injured when intraneuronal levels of glucose become sufficiently high to saturate the normal metabolic pathway for the carbohydrate or when blood supply to the nerve becomes perturbed because of perineural vascular changes. Although all nerve fibers 
Hamed et al. Physical Therapy and Rehabilitation 2014,

may be injured by these processes only small myelinated and unmyelinated fibers that conduct pain and temperature information are the most affected. Once damaged, the axons of these small-diameter nerve fibers undergo regeneration, and pain may occur through abnormal activation of damaged or regenerating small-diameter nociceptive fibers [25].

Lower extremity functional scale as a secondary outcome measures did not show a significant difference between both groups which could be due to the exercises programs that were provided for both groups. Exercises were proved to improve muscle power in both diabetic and non diabetic patients which in turn improve their functional ability. However, the high intensity interval training group had a higher change score than the moderate intensity aerobic training.

Polyneuropathy causes atrophy of the intrinsic muscles of the foot, particularly the dorsal and plantar flexors of the foot contributing to motor dysfunction, limited ankle range of motion and functional difficulties in the lower extremity [26]. Isokinetic isokinetic/iso.ki.net.ic/(-ki-net'ik) maintaining constant torque or tension as muscles shorten or lengthen; see isokinetic exercise, under exercise. muscle strength testing strength testing, $n$ assessment procedure to determine the contractile strength of a muscle. Showed $21 \%$ reduction in muscle strength in both ankle dorsal/plantar flexors and knee flexors/extensors of individuals with neuropathy when compared to age matched subjects without diabetes [27]. Exercise can potentially strengthen the atrophied muscles in persons with diabetic peripheral neuropathy, particularly the ankle dorsal/plantar flexors and knee extensors/flexors. Improved muscle strength around the ankle joint may provide more foot control for individuals with diabetic peripheral neuropathy and increase muscle ankle mobility during the heel strike phase; ultimately improving functional outcome for those patients [28].

Debate exists as to whether or not strength exercises will have a positive effect on the motor function that has been affected by peripheral neuropathy. For example, according to Mueller and colleges, it is doubtful that increases in strength can be made in muscles with severe peripheral neuropathy. However, Cavanagh suggested that increases in strength can be made in muscle fibers that have not yet been affected by peripheral neuropathy, allowing the individual to maximize the output of the muscle fibers that have been unaffected by neuropathy consequently improving their functional abilities [29]. In the current study exclusion of severe polyneuropathic complications were one of our exclusion criteria of the patients. Consequently, our study supports the Cavanagh's suggestion.

Although waist circumference showed a significant reduction in the study group compared to control group, body weight and body mass index did not show a significant difference between both groups. However, only the study group showed a significant reduction. These results suggested that the reduction of body weight and body mass index was due to high intensity interval training program. The reduction of waist circumference in both groups could be due to the fact that exercises increase muscle strength generally, and consequently increase its tension that in turn pull the internal viscera back inside the plural cavity thus reducing the waist circumference. Moreover, the non significant reduction of body weight and body mass index could be referred to limited diet control as the majority of patients did not follow specific diet control program which was one of our study limitations. Our study confirmed the study of Thomas et al., [30] who performed meta-analysis of randomized controlled trials with duration of intervention of $>8$ weeks, and the only difference between the intervention and comparison groups was a well-documented exercise programme (aerobic fitness or high intensity resistance training exercise). Compared with the controls, the exercise interventions significantly improved glycemic control. This result was both statistically and clinically significant. However, there was no significant difference between groups in whole body mass. The author suggested that visceral adipose tissue decreased with exercise and subcutaneous adipose tissue was also reduced, and participants in the exercise groups were likely to have developed muscle, heavier than adipose tissue.

Many studies [31,32] found a significant relationship between exercises and glycemic control which confirm our findings concerning oral glucose tolerance test. In our study there was a significant reduction of fasting blood glucose, 60 min, 90 min and 120 min post prandial was obtained from our results after treatment compared to before with higher change score in the study group. It was suggested that exercise, in addition to diet modification and medication, has been recommended as one of the three main components of glycemic control. Regular exercise can not only lower the amount of glycated hemoglobin ( $\mathrm{HbA} 1 \mathrm{C})$ in diabetics, but also would decrease the prevalence of hyperglycemia in these patients [33].

A recent trial evaluated the effects of one session of exertion in reducing serum levels of glucose in diabetic patients. This study showed that the total time of hyperglycemia, may decrease about $40 \%$ up to 24 hours after each session of exercise. Researchers determined that the effect of this exertion in reducing postprandial hyperglycemia equalizes the effect of limiting calorie intake or use of anti hyperglycemic drugs in these patients. Exercise may increase body's response to intrinsic insulin, by multiple mechanisms including increasing the amount of transporters of glucose into the muscle cells, increasing of insulin receptor substrates and last but not least, increasing the muscle mass, given that more than $75 \%$ of the glucose uptake in response to insulin is by the muscular tissue. The fatty acids released from adipose tissue, concentrating inside the myocytes reduce the glucose transportation onto the cell membrane. Exercise, however, will reduce the fatty acid accumulation within the myocytes, by oxidizing them [34].

According to the results of the present study, high intensity interval training program was found to have profound results more than moderate intensity interval training. These results 
Hamed et al. Physical Therapy and Rehabilitation 2014,

are in accordance with Gulve [35] who stated that high intensity interval training may have greater potential than steady-state exercise to improve glycemic control and reduce visceral fat. Furthermore, increased fat oxidation after high intensity interval training may occur as a result of the need to remove lactate and $\mathrm{H}+$ and to resynthesize glycogen. Uncoupled respiration, protein turnover, and sympathetic nervous system activity may also contribute to increased energy expenditure and fat oxidation after exercise. Also, high intensity interval training may also have a suppressive effect on appetite as exposing rats to hard exercise has been repeatedly reported to reduce food intake. One of the characteristics of the high intensity interval training is that it involves markedly required minimal time commitment making it a strategy to accrue adaptations and possible health benefits, compared to traditional aerobic exercise programs. Thus high intensity exercise improves fitness, insulin resistance, skeletal muscle, subcutaneous, and abdominal fat loss [36]. Trapp et al., [16] found that high intensity interval exercises three times per week for 15 weeks, compared to the same frequency of steady state exercise was associated with significant reductions in total body fat, subcutaneous leg and trunk fat, and insulin resistance in young women. The lack of complete consistency in body weight and body mass index results between our study and Trapp's study may be due to some factors. First, age difference,: our study main age was $48.23 \pm 2.4$ and the other study mean age was $20.2 \pm 2.0$ years that may have a higher metabolic rate than our study patients. Second, our study patients were suffering from neuropathic pain which limit their activities more than the other study patients. Third, the inconsistency is likely explained by differences in the experimental design and protocol.

This study is limited mainly to have long term follow up study as patients could not follow up with our clinic after long time due to the political and social upheavals in our country recently. Also, patients did not follow a diet control program which results in non significant, but actual, weight loss.

\section{Conclusion}

The current study was the first to investigate the effect of high intensity interval training on diabetic obese women with polyneuropathy compared to moderate intensity aerobic training. Three days per week for 15 weeks of high intensity interval training wais found to be more effective than moderate intensity aerobic training in reducing neuropathic pain, hyperglycemia, and waist circumference. However, lower extremity functional scale, body weight and body mass index did not improve significantly. Further research is needed, to include larger population, perform follow up study and change the population characteristics (gender and age).

\section{Implications for rehabilitation}

1. Reduction of pain results in improving functional abilities among women with diabetic polyneuropathy.

2. High intensity exercises and glycemic control are effective in reducing neuropathic pain and improving the patient's quality of life.

\section{Competing interests}

The authors declare that they have no competing interests.

Authors' contributions

\begin{tabular}{|l|c|c|}
\hline Authors' contributions & NSH & NALAR \\
\hline Research concept and design & $\checkmark$ & $\checkmark$ \\
\hline Collection and/or assembly of data & $\checkmark$ & $\checkmark$ \\
\hline Data analysis and interpretation & $\checkmark$ & $\checkmark$ \\
\hline Writing the article & $\checkmark$ & $\checkmark$ \\
\hline Critical revision of the article & $\checkmark$ & $\checkmark$ \\
\hline Final approval of article & $\checkmark$ & $\checkmark$ \\
\hline Statistical analysis & $\checkmark$ & $\checkmark$ \\
\hline
\end{tabular}

Acknowledgement

Special thanks for Dr. Maher Ahmad Mahdi, Assistant Professor of English Literature, Helwan University, ARE, for helping in the linguistic revision of this manuscript. Our gratitude for all the study participants in the study.

\section{Publication history}

Editor: Mohammad H. Hadadzadeh, Wheeling Jesuit University, USA. Received: 05-Mar-2014 Final Revised: 31-Mar-2014

Accepted: 19-Apr-2014 Published: 14-Jun-2014

\section{References}

1. Deshpande AD, Harris-Hayes M and Schootman M. Epidemiology of diabetes and diabetes-related complications. Phys Ther. 2008; 88:125464. | Article | PubMed Abstract | PubMed Full Text

2. Kulie T, Slattengren A, Redmer J and Counts H. Obesity and Women's Health: An Evidence-Based Review: Clinical Review. J Am Board Fam Med. 2011; 24:75-85. | Pdf

3. Frykberg RG, Lavery LA, Pham H, Harvey C, Harkless L and Veves A. Role of neuropathy and high foot pressures in diabetic foot ulceration. Diabetes Care. 1998; 21:1714-9. | Article I PubMed

4. Conner-Kerr T and Templeton MS. Chronic fall risk among aged individuals with type 2 diabetes. Ostomy Wound Manage. 2002; 48:2834. | Article | PubMed

5. Leonard DR, Farooqi MH and Myers S. Restoration of sensation, reduced pain, and improved balance in subjects with diabetic peripheral neuropathy: a double-blind, randomized, placebo-controlled study with monochromatic near-infrared treatment. Diabetes Care. 2004; 27:16872. | Article | PubMed

6. Daousi C, MacFarlane IA, Woodward A, Nurmikko TJ, Bundred PE and Benbow SJ. Chronic painful peripheral neuropathy in an urban community: a controlled comparison of people with and without diabetes. Diabet Med. 2004; 21:976-82. | Article | PubMed

7. Balducci S, Parisi L, Leonetti F, Di Biase N, Calandriello E, Di Mario U and Fallucca $F$. Long-term exercise training delayed the onset of peripheral neuropathy in diabetic patients suggested a true preventive action as well. Diabetes. 2004; 53:A91-A92.

8. Friedlander AL, Jacobs KA, Fattor JA, Horning MA, Hagobian TA, Bauer TA, Wolfel EE and Brooks GA. Contributions of working muscle to whole body lipid metabolism are altered by exercise intensity and training. Am J Physiol Endocrinol Metab. 2007; 292:E107-16. | Article | PubMed

9. Sigal RJ, Kenny GP, Wasserman DH, Castaneda-Sceppa C and White RD. 
Hamed et al. Physical Therapy and Rehabilitation 2014,

Physical activity/exercise and type 2 diabetes: a consensus statement from the American Diabetes Association. Diabetes Care. 2006; 29:14338. | Article | PubMed

10. Verity LS. Diabetes Mellitus and Exercise. In: Kaminsky LA. ACSMQ s Resource Manual for Guidelines for Exercise Testing and Prescription. $5^{\text {th }}$ edition. Philadelphia, Lippincott Williams \& Wilkins 2006; 470-9.

11. Babraj JA, Vollaard NB, Keast C, Guppy FM, Cottrell G and Timmons JA. Extremely short duration high intensity interval training substantially improves insulin action in young healthy males. BMC Endocr Disord. 2009; 9:3. | Article | PubMed Abstract | PubMed Full Text

12. Gibala MJ and McGee SL. Metabolic adaptations to short-term highintensity interval training: a little pain for a lot of gain? Exerc Sport Sci Rev. 2008; 36:58-63. | Article | PubMed

13. Bennett $M$. The LANSS Pain Scale: the Leeds assessment of neuropathic symptoms and signs. Pain. 2001; 92:147-57. | Article | PubMed

14. Binkley JM, Stratford PW, Lott SA and Riddle DL. The Lower Extremity Functional Scale (LEFS): scale development, measurement properties, and clinical application. North American Orthopaedic Rehabilitation Research Network. Phys Ther. 1999; 79:371-83. | Article | PubMed

15. Sanz C, Gautier JF and Hanaire H. Physical exercise for the prevention and treatment of type 2 diabetes. Diabetes Metab. 2010; 36:346-51. | Article | PubMed

16. Trapp EG, Chisholm DJ, Freund J and Boutcher SH. The effects of highintensity intermittent exercise training on fat loss and fasting insulin levels of young women. Int J Obes (Lond). 2008; 32:684-91. | Article | PubMed

17. Swain DP and Leutholtz BC. Heart rate reserve is equivalent to \%VO2 reserve, not to \%VO2max. Med Sci Sports Exerc. 1997; 29:410-4. | Article I PubMed

18. Kaki AM, El-Yaski AZ and Youseif E. Identifying neuropathic pain among patients with chronic low-back pain: use of the Leeds Assessment of Neuropathic Symptoms and Signs pain scale. Reg Anesth Pain Med. 2005; 30:422-8. | Article | PubMed

19. Finch E, Brooks D, Stratford PW and Mayo NE. Physical rehabilitation outcome measures: A guide to enhanced clinical decision-making Baltimore (MD): Lippincott Williams \& Wilkins. 2002.

20. Jones RL and Nzekwu MM. The effects of body mass index on lung volumes. Chest. 2006; 130:827-33. | Article | PubMed

21. University of Minnesota Medical Center, Fairview Collaborative Studies Clinical Laboratory Minneapolis, Minnesota. Laboratory Procedure Manual: Fasting Glucose in Plasma NHANES; April: 2007-2008.

22. Andersen $\mathrm{H}$, Gadeberg PC, Brock $B$ and Jakobsen J. Muscular atrophy in diabetic neuropathy: a stereological magnetic resonance imaging study. Diabetologia. 1997; 40:1062-9. | Article | PubMed

23. Andersen H, Poulsen PL, Mogensen CE and Jakobsen J. Isokinetic muscle strength in long-term IDDM patients in relation to diabetic complications. Diabetes. 1996; 45:440-5 IDDM Insulin-dependent diabetes mellitus; now known as type 1 diabetes. . Article | PubMed

24. Fisher MA, Langbein WE, Collins EG, Williams $K$ and Corzine L. Physiological improvement with moderate exercise in type II diabetic neuropathy. Electromyogr Clin Neurophysiol. 2007; 47:23-8. I PubMed

25. Leone C, Biasiotta A, La Cesa S, Di Stefano G, Cruccu Gi and Truini A. Pathophysiological Mechanisms of Neuropathic Pain. Future Neurology. 2011; 6:497-509.

26. The effect of intensive treatment of diabetes on the development and progression of long-term complications in insulin-dependent diabetes mellitus. The Diabetes Control and Complications Trial Research Group. N Engl J Med. 1993; 329:977-86. | Article | PubMed

27. Shankarappa SA, Piedras-Renteria ES and Stubbs EB, Jr. Forced-exercise delays neuropathic pain in experimental diabetes: effects on voltageactivated calcium channels. J Neurochem. 2011; 118:224-36. | Article | PubMed

28. Giacomozzi C, Caselli A, Macellari V, Giurato L, Lardieri L and Uccioli L. Walking strategy in diabetic patients with peripheral neuropathy. Diabetes Care. 2002; 25:1451-7. | Article | PubMed

29. Mueller MJ, Minor SD, Sahrmann SA, Schaaf JA and Strube MJ.
Differences in the gait characteristics of patients with diabetes and peripheral neuropathy compared with age-matched controls. Phys Ther. 1994; 74:299-308. | Article | PubMed

30. Thomas DE, Elliott EJ and Naughton GA. Exercise for type 2 diabetes mellitus. Cochrane Database Syst Rev. 2006; CD002968. | Article | PubMed

31. Colberg SR, Sigal RJ, Fernhall B, Regensteiner JG, Blissmer BJ, Rubin RR, Chasan-Taber L, Albright AL and Braun B. Exercise and type 2 diabetes: the American College of Sports Medicine and the American Diabetes Association: joint position statement executive summary. Diabetes Care. 2010; 33:2692-6. | Article | PubMed Abstract | PubMed Full Text

32. Zeitler P, Hirst K, Pyle L, Linder B, Copeland K, Arslanian S, Cuttler L, Nathan DM, Tollefsen S, Wilfley D and Kaufman F. A clinical trial to maintain glycemic control in youth with type 2 diabetes. N Engl J Med. 2012; 366:2247-56. | Article | PubMed Abstract | PubMed Full Text

33. Verity LS. Diabetes Mellitus and Exercise. In: Kaminsky LA. ACSMQ s Resource Manual for Guidelines for Exercise Testing and Prescription. $5^{\text {th }}$ edition. Philadelphia, Lippincott Williams \& Wilkins. 2006; 470-9.

34. Praet SF, Manders RJ, Lieverse AG, Kuipers H, Stehouwer CD, Keizer $\mathrm{HA}$ and van Loon LJ. Influence of acute exercise on hyperglycemia in insulin-treated type 2 diabetes. Med Sci Sports Exerc. 2006; 38:2037-44. | Article | PubMed

35. Gulve EA. Exercise and glycemic control in diabetes: benefits, challenges, and adjustments to pharmacotherapy. Phys Ther. 2008; 88:1297-321. | Article | PubMed

36. Stiegler $P$ and Cunliffe $A$. The role of diet and exercise for the maintenance of fat-free mass and resting metabolic rate during weight loss. Sports Med. 2006; 36:239-62. | Article | PubMed

\section{Citation:}

Hamed NS and Raoof NALA. Effect of high intensity interval training on diabetic obese women with polyneuropathy: a randomized controlled clinical trial. Phys Ther Rehabil. 2014; 1:4.

http://dx.doi.org/10.7243/2055-2386-1-4 